\title{
Inferring computational function of neuronal networks from multi-electrode array recordings: an evolutionary approach
}

Thomas R Kiehl

\author{
From Twentieth Annual Computational Neuroscience Meeting: CNS*2011 \\ Stockholm, Sweden. 23-28 July 2011
}

The availability of microelectrode array systems (MEA's) has increased dramatically in recent years. Along with this increase in availability, these systems have also grown in capability. Modern systems stimulate and record in-vitro neuronal networks on an increasing number of channels. Closed-loop capabilities further expand the functionality of these systems. Future miniaturization of these systems and commensurate increased resolution promises a continued rise in the volume of data being produced in this domain.

It is difficult to determine if analysis tools are keeping pace with data generation. As of a few years ago Brown et al. saw a distinct need for investment in this vein[1]. It seems likely that data acquisition will continue to outstrip analysis just as it has in other bioinformatics domains. In 2006 Waganaar et al made available an extensive data set or recorded microelectrode array activity [2]. This data set contained both spontaneous and stimulated activity recorded regularly, from 58 unique cultures, of varying cell density, over a period of five weeks. While this study is referenced by hundreds of presenters and researchers, only a few groups have published analyses of this data. Patnaik et al stand out in that very small cohort as they sought to infer network structure from this data set based on the last 5 days of recordings from 6 cultures[3]. It is likely that these cultures were more static at this stage and were no longer developing connections at the same rate one may have observed in earlier time points.

Genetic algorithms (GA's) and other evolutionary computing techniques have a proven track record in temporal knowledge discovery, network analysis, and

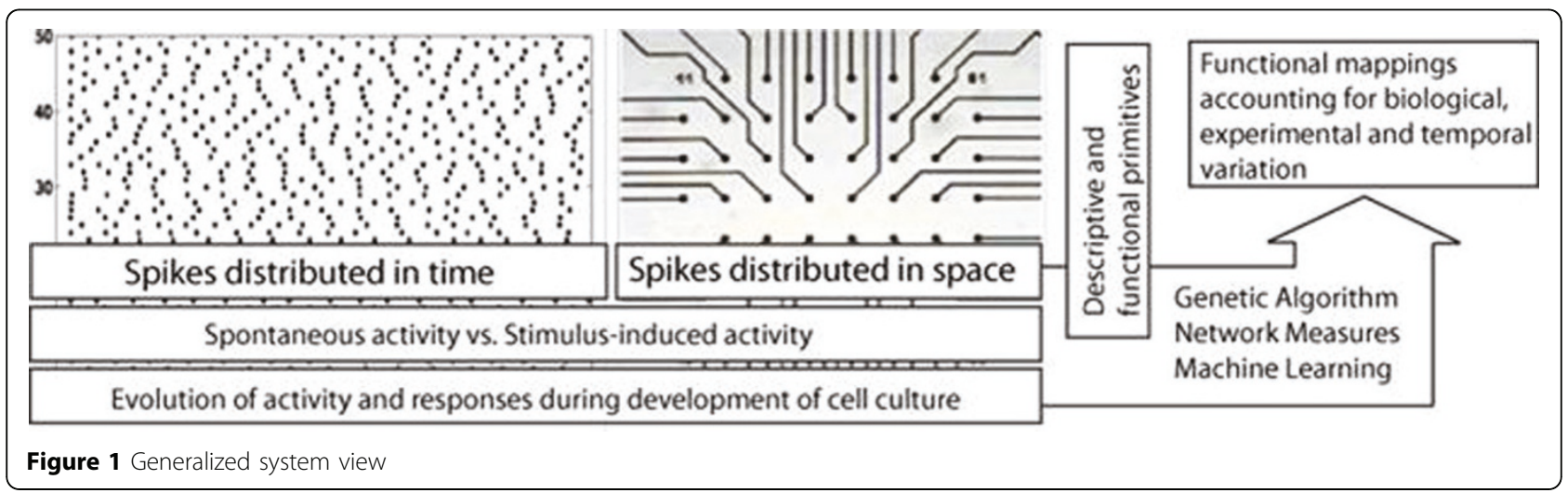

Correspondence: tkiehl@albany.edu

Nanobioscience Constellation, College of Nanoscale Science and Eng.,

University at Albany, Albany, NY, USA

Full list of author information is available at the end of the article

C Biomed Central

(c) 2011 Kiehl; licensee BioMed Central Ltd. This is an open access article distributed under the terms of the Creative Commons Attribution License (http://creativecommons.org/licenses/by/2.0), which permits unrestricted use, distribution, and reproduction in any medium, provided the original work is properly cited. 
machine learning[4][5]. In this work we demonstrate the feasibility of using a GA to tease out temporal and spatial relationships in the neuronal networks. Our analysis yields a functional and explanatory model of signal propagation on MEA's and the development of neuronal networks in-vitro. As shown in figure 1 we seek to incorporate a broad range of MEA activity. The descriptive nature of the output from the evolutionary system can be tuned to include domain specific inferences. These models can present more actionable information for network design than their purely statistical counterparts.

Published: 18 July 2011

\section{References}

1. Brown EN, Kass RE, Mitra PP: Multiple neural spike train data analysis: state-of-the-art and future challenges. Nat Neurosci 2004, 7:456-461.

2. Wagenaar D, Pine J, Potter S: An extremely rich repertoire of bursting patterns during the development of cortical cultures. BMC Neuroscience 2006, 7:11.

3. Patnaik D, Sastry $P$, Unnikrishnan K: Inferring neuronal network connectivity from spike data: A temporal data mining approach. Scientific Programming 2008, 16:49-77.

4. Goldberg DE: Genetic Algorithms in Search, Optimization, and Machine Learning. Addison-Wesley Professional; 11989.

5. Fogel GB: Computational intelligence approaches for pattern discovery in biological systems. Briefings in Bioinformatics 2008, 9:307-316.

doi:10.1186/1471-2202-12-S1-P167

Cite this article as: Kiehl: Inferring computational function of neuronal networks from multi-electrode array recordings: an evolutionary approach. BMC Neuroscience 2011 12(Suppl 1):P167.

\section{Submit your next manuscript to BioMed Central} and take full advantage of:

- Convenient online submission

- Thorough peer review

- No space constraints or color figure charges

- Immediate publication on acceptance

- Inclusion in PubMed, CAS, Scopus and Google Scholar

- Research which is freely available for redistribution

Submit your manuscript at www.biomedcentral.com/submit 